\title{
Experimental results for a magnetic refrigerator using three different types of magnetocaloric material regenerators
}

\author{
Engelbrecht, Kurt; Bahl, Christian Robert Haffenden; Nielsen, Kaspar Kirstein
}

Published in:

International Journal of Refrigeration

Link to article, DOI:

10.1016/j.jirefrig.2010.11.014

Publication date:

2011

Link back to DTU Orbit

Citation (APA):

Engelbrecht, K., Bahl, C. R. H., \& Nielsen, K. K. (2011). Experimental results for a magnetic refrigerator using three different types of magnetocaloric material regenerators. International Journal of Refrigeration, 34(4), 11321140. https://doi.org/10.1016/j.jirefrig.2010.11.014

\section{General rights}

Copyright and moral rights for the publications made accessible in the public portal are retained by the authors and/or other copyright owners and it is a condition of accessing publications that users recognise and abide by the legal requirements associated with these rights.

- Users may download and print one copy of any publication from the public portal for the purpose of private study or research.

- You may not further distribute the material or use it for any profit-making activity or commercial gain

- You may freely distribute the URL identifying the publication in the public portal 


\title{
Experimental results for a magnetic refrigerator using three different types of magnetocaloric material regenerators
}

\author{
K. Engelbrecht*, C. R. H. Bahl* \\ Fuel Cells and Solid State Chemistry Division \\ Risø National Laboratory for Sustainable Energy \\ Technical University of Denmark - DTU \\ Building 228, P.O. Box 49, DK-4000 Roskilde, Denmark \\ K. K. Nielsen* \\ Department of Mechanical Engineering, Technical University of Denmark \\ Produktionstorvet, building 425, room 020, $2800 \mathrm{Kgs}$. Lyngby
}

\begin{abstract}
Magnetic refrigeration is a potentially environmentally-friendly alternative to vapor compression technology because it has a potentially higher coefficient of performance and does not use a gaseous refrigerant. The active magnetic regenerator refrigerator is currently the most common magnetic refrigeration device for near room temperature applications, and it is driven by the magnetocaloric effect in the regenerator material. Several magnetocaloric materials with potential magnetic refrigeration applications have recently been developed and characterized; however, few of them have been tested in an experimental device. This paper compares the performance of three magnetocaloric material candidates for AMRs, $\mathrm{La}(\mathrm{Fe}, \mathrm{Co}, \mathrm{Si})_{13}$, ( $\left.\mathrm{La}, \mathrm{Ca}, \mathrm{Sr}\right) \mathrm{MnO}_{3}$
\end{abstract}

${ }^{*}$ Corresponding author. Telephone number: +45 46775649. Fax: +4546775858 .

Email address: kuen@risoe.dtu.dk (K. Engelbrecht) 
and $\mathrm{Gd}$, in an experimental active magnetic regenerator with a parallel plate geometry. The performance of single-material regenerators of each magnetocaloric material family were compared. In an attempt to improve system performance, graded two-material regenerators were made from two different combinations of $\mathrm{La}(\mathrm{Fe}, \mathrm{Co}, \mathrm{Si})_{13}$ compounds having different magnetic transition temperatures. One combination of the $\mathrm{La}(\mathrm{Fe}, \mathrm{Co}, \mathrm{Si})_{13}$ materials yielded a higher performance, while the performance of the other combination was lower than the single-material regenerator. The highest no-load temperature span was achieved by the Gd regenerator.

Keywords: Magnetic refrigerator, Regenerator, Magnetic property, Experimentation 


\section{Nomenclature}

\begin{tabular}{|ll|}
\hline Variables & \\
$A_{\mathrm{f}}$ & cross-sectional area for fluid flow $\left(\mathrm{m}^{2}\right)$ \\
$c$ & specific heat $\left(\mathrm{J} \mathrm{kg}^{-1} \mathrm{C}^{-1}\right)$ \\
$\Delta T_{a d}$ & adiabatic temperature change with magnetization $\left({ }^{\circ} \mathrm{C}\right)$ \\
$\Delta T_{A M R}$ & operating temperature span of the AMR $\left({ }^{\circ} \mathrm{C}\right)$ \\
$U$ & utilization ratio $($ Eq. 1$)$ \\
$v$ & velocity $\left(\mathrm{m} \mathrm{s}^{-1}\right)$ \\
$V$ & volume $\left(\mathrm{m}^{3}\right)$ \\
$\rho$ & density $\left(\mathrm{kg} \mathrm{m}{ }^{-3}\right)$ \\
$\tau$ & total cycle time (s) \\
$\tau_{1}$ & time for the magnetization or demagnetization $(\mathrm{s})$ \\
$\tau_{2}$ & time for the fluid flow process in the AMR cycle $(\mathrm{s})$ \\
$\zeta$ & regeneration ratio (Eq. 2) \\
\hline
\end{tabular}

\begin{tabular}{|ll|}
\hline Subscripts & \\
$f$ & fluid \\
$s$ & solid regenerator material \\
\hline
\end{tabular}




\section{Introduction}

Active magnetic regenerative (AMR) refrigeration systems represent an attractive alternative to vapor compression refrigeration and air-conditioning systems. AMR systems use a solid magnetocaloric refrigerant rather than a fluorocarbon working fluid, and it interacts with the environment via a heat transfer fluid. Because the solid refrigerant has essentially zero vapor pressure, AMR systems have no Ozone Depletion Potential (ODP) and no direct Global Warming Potential (GWP). The heat transfer fluid will likely be aqueous and will therefore have minimal environmental impact. In theory, a well-designed AMR system can be competitive with or even more efficient than vapor compression systems, provided that the volume of the active magnetic regenerator is sufficiently large (Engelbrecht et al., 2006). There has been an increased effort in recent years to develop new AMR systems and magnetocaloric materials (Gschneidner Jr et al., 2005).

Recently, the performance of several prototype AMR machines has been reported (Tura and Rowe (2009), Gschneidner and Pecharsky (2008), Nakamura et al. (2008)). Many of these devices use packed sphere regenerators, which offer relatively easy construction of the regenerator, high heat transfer performance, and the ability to use multiple magnetocaloric materials. However, packed sphere regenerators have significantly higher pressure drop than many other regenerator geometries, including parallel plate regenerators (Barclay and Sarangi, 1984). The high pressure drop associated with packed sphere regenerators increases the necessary pump work and reduces the theoretical performance limit of the AMR technology. Parallel plates offer a potentially high-performance alternative to packed sphere regenera- 
tors, due to their relatively low pressure drop to heat transfer performance (Sarlah, 2008).

Many magnetocaloric materials with potential applications in room temperature AMR devices have recently been developed and characterized (Gschneidner Jr et al., 2005). Although experimental AMR results have been reported for regenerators made of $\mathrm{Gd}_{5}(\mathrm{Si}, \mathrm{Ge})_{4}$ ( $\mathrm{Lu}$ et al., 2005) and $\mathrm{La}(\mathrm{Fe}, \mathrm{Si})_{13} \mathrm{H}_{x}$ (Zimm et al., 2006), the majority of experimental results are for Gd or Gd alloy regenerators. This paper presents experimental results for an AMR device using parallel plate regenerators made of three different types of magnetocaloric materials and compares the results. The materials are gadolinium $(\mathrm{Gd})$, three different intermetallic materials of the type $\mathrm{La}(\mathrm{Fe}, \mathrm{Co}, \mathrm{Si})_{13}$ and a ceramic material of the type $\mathrm{La}_{0.67} \mathrm{Ca}_{0.26} \mathrm{Sr}_{0.07} \mathrm{Mn}_{1.05} \mathrm{O}_{3}$, which is referred to as LCSM

Another goal of the research presented here is to improve the general performance of the prototype AMR presented in this paper, and several techniques were evaluated. It has been shown experimentally by Rowe and Tura (2006), among others, that building a regenerator from several materials can improve AMR performance. By choosing the magnetic transition temperature of the regenerator materials to match the local temperature experienced by the material, the magnetocaloric effect in the regenerator and the system performance are increased. Experimental results for beds of multiple compositions of $\mathrm{La}(\mathrm{Fe}, \mathrm{Co}, \mathrm{Si})_{13}$ compounds (layered regenerators) are presented here and compared to similar results with a single material regenerator. Methods to prevent corrosion of the $\mathrm{La}(\mathrm{Fe}, \mathrm{Co}, \mathrm{Si})_{13}$ plates and a technique to reduce thermal conduction losses through the regenerator housing wall are also pre- 
sented.

\section{Experimental Apparatus}

A single-regenerator reciprocating AMR test machine has been built and used to test different magnetocaloric materials and regenerator designs. The volume of the regenerator, not including housing and external hardware, is approximately $15 \mathrm{~cm}^{3}$, and the magnetic field is provided by a Halbach cylinder type permanent magnet assembly with an average flux density in the bore of 1.03 Tesla. The magnet, which is described by Bjørk et al. (2010a), has a bore of $42 \mathrm{~mm}$ and a height of $50 \mathrm{~mm}$. Magnetization and demagnetization of the regenerator are achieved by moving the regenerator vertically relative to the stationary magnet by use of a stepper motor. The test device is described in detail by Bahl et al. (2008) and Engelbrecht et al. (2009), and was designed such that the regenerator housing can be easily changed, allowing a range of regenerator designs to be tested quickly. However, only flat plate regenerators have been tested up to this point. The operating parameters for this device are the stroke of the fluid displacer, the velocity of the fluid displacer, and the speed at which the regenerator is moved into and out of the magnetic field. These parameters dictate the cycle time and fluid flow of the AMR cycle.

In order to test the machine's performance over a range of operating temperatures and to better control the experimental conditions, the device has been placed in a temperature controlled cabinet with the hot reservoir in thermal contact with the air in the cabinet. Therefore in this paper, the temperature inside the cabinet is considered the ambient temperature. 
There is a heat exchanger in the hot reservoir of the prototype that maintains the reservoir at a temperature that is generally within $1{ }^{\circ} \mathrm{C}$ of the ambient temperature. Because each material tested in this research has a different transition temperature, it is important to modify the operating temperature of the machine accordingly. In each experiment, the ambient temperature was set slightly above the material's transition temperature to ensure that the system operated near its optimal temperature range. Due to the nature of this test device, high cycle frequencies are not feasible and therefore cooling power is relatively low. This work emphasizes optimizing the no-load temperature span of the system. Cycle parameters such as cycle frequency and fluid flow rate are generally chosen to optimize no-load temperature span.

A simple schematic of the test machine is given in Fig. 1. The regenerator has a Perspex tube screwed onto each end, with the hot reservoir located in the tube above the regenerator and the cold reservoir in the tube below. There is a resistance heater installed in the regenerator's cold reservoir to simulate a cooling load. The heater power is measured by the potential and current in the heater power supply. The uncertainty is approximately $1 \%$. The heat transfer fluid is moved through the regenerator by means of a displacer in the cold reservoir. The temperatures of the hot reservoir, cold reservoir and ambient are measured by type $\mathrm{T}$ thermocouples that were calibrated in situ. The uncertainty of each temperature measurement is estimated to be $0.2{ }^{\circ} \mathrm{C}$.

The entire device is placed in contact with the same ambient temperature; however, the hot reservoir is thermally linked to ambient via a forced convection heat exchanger that uses a secondary heat transfer fluid while the 
cold reservoir is insulated using foam insulation, and the outer wall of the regenerator housing is in contact with the ambient. All thermal losses through the regenerator housing and cold reservoir are to the ambient temperature. The motor that moves the regenerator relative to the magnetic field and the motor that moves the displacer pushing heat transfer fluid through the regenerator are independent and software-controlled. The length of the magnetization and demagnetization steps are limited by the motors that move the regenerator. The minimum time for magnetization, $\tau_{1}$, for this device is approximately $0.6 \mathrm{~s}$, and the fluid flow period, $\tau_{2}$ is determined by the displacer stroke length and velocity.

\subsection{Regenerator Housings}

The purpose of the test machine described here is to test a range of AMR designs quickly under consistent experimental conditions. To allow this, the regenerator housings were fabricated using rapid prototyping techniques. Rapid prototyping was chosen because a range of detailed geometries can be produced in a single piece, eliminating fluid leakage and simplifying fabrication. Some types of rapid prototyping processes use plastics with relatively low thermal diffusivities, such as acrylic or nylon, which reduces interactions between the heat transfer fluid and regenerator housing compared to other structural materials. The dimensions of the baseline regenerator are $40 \mathrm{~mm}$ in the direction of flow with a rectangular flow opening that is 23 $\mathrm{mm}$ wide by $17 \mathrm{~mm}$ high. Each plate is slid into a $1 \mathrm{~mm}$ tall slot that runs the entire length of the regenerator. Plate spacing is controlled by the height of the ribs between each slot, and the height of each rib can be no less than $0.5 \mathrm{~mm}$ due to manufacturing limitations. The regenerator houses 11 plates 
with the top and bottom plates in direct contact, with the housing to reduce interactions between the heat transfer fluid and regenerator housing. The heat transfer fluid is a mixture of $75 \%$ water and $25 \%$ automotive antifreeze. Consumer antifreeze, which is based on ethylene glycol, was chosen over laboratory grade ethylene glycol because it has corrosion inhibitors that reduce the corrosion of several of the magnetocaloric materials under consideration.

This paper presents results for two different regenerator housings. The first is made using a PolyJet process, where droplets of an acrylic-based polymer are deposited in layers with a thickness of approximately $0.02 \mathrm{~mm}$ and hardened after each deposition. The second is made using a selective laser sintering (SLS) process, where layers of nylon powder approximately $0.1 \mathrm{~mm}$ in thickness are selectively sintered to form the final part. The SLS process was chosen because it could be used to produce a regenerator housing with hollow walls, which reduces conduction to the ambient. The PolyJet process could not be used to make the hollow-walled regenerator housing because the process uses a wax support structure that would be difficult to remove from the space inside the walls. Although some areas of the hollowwalled housing must be solid for hardware installation and structural support, the overall conduction path is reduced by using a hollow wall. Assuming that the hollow volume is filled with quiescent air, the thermal conductivity through the hollow housing and solid housing can be estimated. Using an average distance occupied by the air, the thermal conductivity through the hollow regenerator wall is on average approximately one fourth the value of the conductivity through the solid regenerator housing. The minimum wall thickness is $2.2 \mathrm{~mm}$ for the hollow regenerator housing. 


\section{Magnetocaloric materials tested}

One of the main purposes of this research is to compare different families of magnetocaloric materials in a simple, practical AMR application. This paper presents results for flat plates of commercial grade gadolinium, three compositions of $\mathrm{La}(\mathrm{Fe}, \mathrm{Co}, \mathrm{Si})_{13}$ compounds, and an LCSM compound. The dimension of each plate is $40 \mathrm{~mm}$ in the direction of flow and $25 \mathrm{~mm}$ wide. The gadolinium is in the form of $0.9 \mathrm{~mm}$ flat plates that are $99.99 \%$ pure and was obtained from a commercial source. Gadolinium was chosen because it is historically the most common magnetocaloric material used in AMR prototypes (Yu et al., 2003) due to its availability, relatively high adiabatic temperature change, and low hysteresis. The properties are well known and can be found in Dan'kov et al. (1998), for example.

Three different compounds of $\mathrm{La}(\mathrm{Fe}, \mathrm{Co}, \mathrm{Si})_{13}$ with compositions $\mathrm{LaFe}_{11.06} \mathrm{Co}_{0.86} \mathrm{Si}_{1.08}$, $\mathrm{LaFe}_{11.05} \mathrm{Co}_{0.94} \mathrm{Si}_{1.01}$ and $\mathrm{LaFe}_{10.96} \mathrm{Co}_{0.97} \mathrm{Si}_{1.07}$ were cut into $0.9 \mathrm{~mm}$ thick plates from blocks made from sintered powder by Vacuumschmelze GmbH. According to Bjørk et al. (2010b), the $\mathrm{La}(\mathrm{Fe}, \mathrm{Co}, \mathrm{Si})_{13}$ plates had transition temperatures of approximately $3{ }^{\circ} \mathrm{C}, 13{ }^{\circ} \mathrm{C}$, and $16{ }^{\circ} \mathrm{C}$, repectively. The transition temperatures were chosen to be within approximately $5{ }^{\circ} \mathrm{C}$ of one another, but no numerical optimization of the compositions was performed. The $\mathrm{La}(\mathrm{Fe}, \mathrm{Co}, \mathrm{Si})_{13}$ materials were used to construct single and multi-material regenerators.

The final material tested is $\mathrm{La}_{0.67} \mathrm{Ca}_{0.26} \mathrm{Sr}_{0.07} \mathrm{Mn}_{1.05} \mathrm{O}_{3} \mathrm{LCSM}$ prepared by tape casting to plates of $0.3 \mathrm{~mm}$ thickness. The compound has a transition temperature of $23{ }^{\circ} \mathrm{C}$. It was desired to produce plates with the same dimensions of each material; however, the LCSM plates are thinner than the other 
two material families due to limitations of the tape casting process. LCSM compounds are ceramics and thus corrosion resistant. The plates used in experiments presented here were tape cast then sintered and laser-cut to size. LCSM materials are attractive alternatives to Gd because they have a similar specific isothermal entropy change with magnetization to Gd (Dinesen, 2004), but the basic elements that comprise the materials are less expensive, and the transition temperature of the material can be adjusted. Due to their relatively high specific heat capacity, LCSM compounds have a lower adiabatic temperature change than both $\mathrm{La}(\mathrm{Fe}, \mathrm{Co}, \mathrm{Si})_{13}$ compounds and $\mathrm{Gd}$.

The properties of all five materials that were tested here are summarized in Fig. 2. Figure 2 (b) shows how the transition temperature of the materials can be adjusted to provide the greatest entropy change with magnetization for a given operating temperature. The Gd properties reported were measured by Bjørk et al. (2010b) for the plates used in the experimental device. The figure shows that each material except LCSM exhibits the highest isothermal entropy change of the materials considered for some temperature range, which illustrates how multi-material regenerators can increase the magnetocaloric effect in AMRs. The isothermal entropy change is reported on a volumetric basis in Fig. 2 because it is a more meaningful property for regenerator materials (Gschneidner Jr et al., 2005). When the density of the materials is taken into account, Gd exhibits a significantly higher isothermal entropy change than LCSM. The mass of the magnetocaloric material for regenerators of each magnetocaloric compound are given in Table I. The mass of the regenerator will vary slightly with composition for each $\mathrm{La}(\mathrm{Fe}, \mathrm{Co}, \mathrm{Si})_{13}$ composition and an average density of $7200 \mathrm{~kg} \mathrm{~m}^{-3}$ was used to calculate 
the regenerator mass. The $\mathrm{La}(\mathrm{Fe}, \mathrm{Co}, \mathrm{Si})_{13}$ compounds represent a potential alternative to Gd because they have a higher isothermal entropy change with magnetization than Gd and generally exhibit low hysteresis. The volumetric isothermal entropy change is approximately $60 \%$ higher while the adiabatic temperature change is approximately $30 \%$ lower than Gd. The lower temperature change with magnetization is due to the significantly higher specific heat of the $\mathrm{La}(\mathrm{Fe}, \mathrm{Co}, \mathrm{Si})_{13}$ compounds. The $\mathrm{La}(\mathrm{Fe}, \mathrm{Co}, \mathrm{Si})_{13}$ plates also exhibit significantly higher corrosion and are more brittle than Gd.

\section{Experimental Results}

The prototype AMR was operated over a range of conditions for ambient temperature, regenerator materials, cycle time, and utilization, $U$, which is defined in Eq. (1). For each experiment, the cooling power and temperatures of the reservoirs and ambient were recorded.

$$
U=\frac{v_{f} A_{f} \tau_{2} \rho_{f} c_{f}}{V_{s} \rho_{s} c_{s}}
$$

where $\tau_{2}$ is the time for a blow period, $v_{\mathrm{f}}$ is the fluid velocity, $A_{\mathrm{f}}$ is the cross-sectional area available for fluid flow, $\rho_{\mathrm{f}}$ is the fluid density, $c_{\mathrm{f}}$ is the specific heat of the fluid, and $V_{\mathrm{s}}$ is the volume of the solid regenerator material. The average specific heat of gadolinium used to calculate the utilization is assumed to be $260 \mathrm{~J} \mathrm{~kg}^{-1} \mathrm{~K}^{-1}$ based on data from Dan'kov et al. (1998). The utilization represents the ratio of the thermal capacity of the fluid that moves into the regenerator to the thermal capacity of the solid regenerator material. 
The control software for the machine presented here breaks the AMR cycle into four separate processes such that the cold-to-hot blow starts only when the regenerator is fully magnetized, and the hot-to-cold blow starts after the regenerator is moved fully out of the magnetic field. Therefore, if the time for any single process is changed, the cycle time is also changed. As a measure of the performance of the regenerator design, a figure of merit, the regeneration ratio, is defined below.

$$
\zeta=\frac{\Delta T_{A M R}}{\Delta T_{a d}}
$$

where $\Delta T_{\mathrm{AMR}}$ is the operating temperature span of the device and $\Delta T_{\mathrm{ad}}$ is the maximum adiabatic temperature change of the magnetocaloric material from 0 to the maximum field in the device. The ratio of regeneration describes how the operating temperature span of the AMR compares to the adiabatic temperature change of the material. The parameters used to calculate $U$ and $\zeta$ are given in Table II.

\subsection{Results for gadolinium}

In order to determine operating parameters that are near optimal for the Gd regenerator, the solid PolyJet regenerator housing with Gd plates was used for a range of experiments where the fluid flow rates and cycle times were varied. Operating conditions that result in the highest no-load temperature span were determined experimentally and they are shown in Table III. The optimum operating conditions were found to be only a weak function of temperature, provided the operating temperature was near the transition temperature of Gd. 
Using the operating conditions from Table III, the test machine was run with Gd and both the solid and hollow-walled regenerator housings for a range of ambient temperatures. The no-load temperature span for each experiment is shown in Fig. 3.

Figure 3 shows that the maximum temperature span is achieved at an ambient temperature of approximately $24{ }^{\circ} \mathrm{C}$ for both the solid and hollowwall regenerator housings. It has previously been reported that the optimum hot-end temperature is just above the Curie temperature (Rowe and Tura 2008) and this experiment agrees with that finding. At an ambient temperature of $24{ }^{\circ} \mathrm{C}$, the regenerator operates approximately between $16{ }^{\circ} \mathrm{C}$ and 25 ${ }^{\circ} \mathrm{C}$. The transition temperature is close to the middle of this range, meaning that the entropy change with magnetization of the material is maximized. The hollow regenerator housing generally performs slightly better than the solid housing, but the difference is near the experimental uncertainty for the device which is estimated at approximately $0.2^{\circ} \mathrm{C}$. As the temperature span of the device increases, the performance of the hollow housing may improve relative to the solid housing. However for a temperature span below $10{ }^{\circ} \mathrm{C}$, the benefit of the hollow regenerator housing is relatively small, which suggests that conduction losses through the regenerator housing walls are not a significant loss mechanism for this device.

To test the effect of ambient temperature relative to the hot and cold reservoirs on the temperature span experienced by the regenerator, the operating parameters of the AMR were held constant while the secondary fluid flow rate in the hot heat exchanger was reduced. With the hot heat exchanger effectiveness reduced, the ambient temperature was set to $22.5^{\circ} \mathrm{C}$ 
and the regenerator produced a no-load span of $10.2^{\circ} \mathrm{C}$ between $15.6{ }^{\circ} \mathrm{C}$ and $25.8^{\circ} \mathrm{C}$. This represents a $\zeta$ of 3.2. Thus, the temperature span achieved when the hot reservoir was allowed to rise more than $3{ }^{\circ} \mathrm{C}$ above the ambient increased the no-load temperature span by more than $1{ }^{\circ} \mathrm{C}$. This could be due to the reduced temperature difference between the cold reservoir and ambient or the reduced temperature difference between any location along the regenerator and ambient. Because the losses through the regenerator wall were shown to be relatively small, it is likely that there is a thermal leak from the cold reservoir to the ambient that causes a noticeable reduction in no-load temperature span.

\subsection{Results for $\mathrm{La}(\mathrm{Fe}, \mathrm{Co}, \mathrm{Si})_{13}$ compounds}

Plates of $0.9 \mathrm{~mm}$ thickness have been produced by Vacuumschmelze $\mathrm{GmbH}$ of three compositions of sintered $\mathrm{La}(\mathrm{Fe}, \mathrm{Co}, \mathrm{Si})_{13}$ powder. Each plate is $0.9 \mathrm{~mm}$ thick and $20 \mathrm{~mm}$ long, or half the length of the gadolinium plates discussed above. The layered bed is constructed by butting the two different plates against each other. The solid regenerator housing was run with a single-material regenerator of the $16{ }^{\circ} \mathrm{C}$ transition temperature material over a range of operating conditions, and the system reached a maximum observed no-load temperature span of $7.9{ }^{\circ} \mathrm{C}$ for a utilization of 0.54 , with the regenerator operated between 10.1 and $18.0{ }^{\circ} \mathrm{C}$ while the ambient temperature was $15.6^{\circ} \mathrm{C}$. The corresponding $\zeta$ is 4.3 . Because the volumetric specific heat of these materials is higher than $\mathrm{Gd}$, the fluid flow rate that results in equal utilization is higher for $\mathrm{La}(\mathrm{Fe}, \mathrm{Co}, \mathrm{Si})_{13}$ compounds than $\mathrm{Gd}$. A regenerator comprised of a single $\mathrm{La}(\mathrm{Fe}, \mathrm{Co}, \mathrm{Si})_{13}$ material produces a noticeably lower no-load temperature span than a Gd regenerator operating 
at comparable conditions although the ratio of regeneration is higher. The higher value of $\zeta$ is likely due to the fact that the $\mathrm{La}(\mathrm{Fe}, \mathrm{Co}, \mathrm{Si})_{13}$ material has a higher specific heat than Gd but a lower value of $\Delta T_{\mathrm{ad}}$.

\subsubsection{Two-material $\mathrm{La}(\mathrm{Fe}, \mathrm{Co}, \mathrm{Si})_{13}$ regenerator results}

A two material regenerator was then constructed from the $3{ }^{\circ} \mathrm{C}$ and 16 ${ }^{\circ} \mathrm{C}$ materials and the no-load temperature span was measured for a range of utilizations at an ambient temperature of $13{ }^{\circ} \mathrm{C}$. It was expected that the measured temperature span would be a strong function of utilization, as this commonly determines regenerator performance (Dragutinovic and Baclic, 1998). However, the temperature span exhibited a much stronger dependence on fluid velocity in the flow channel. Therefore, the results are plotted as a function of fluid velocity in Fig. 4.

Indeed, Fig. 4 shows that the dependence of the temperature span on utilization is lower than that of fluid velocity. An ambient temperature of $13{ }^{\circ} \mathrm{C}$ was chosen because it is very near the optimum ambient temperature for this regenerator. It was observed that the no-load temperature span was only a very weak function of ambient temperature between the range of $8{ }^{\circ} \mathrm{C}$ and $15{ }^{\circ} \mathrm{C}$. The data suggest that as long as the ambient temperature is between the Curie temperatures of the two materials, the temperature span will be similar. The performance of the layered $\mathrm{La}(\mathrm{Fe}, \mathrm{Co}, \mathrm{Si})_{13}$ regenerator with Curie temperatures of $3{ }^{\circ} \mathrm{C}$ and $16{ }^{\circ} \mathrm{C}$ failed to produce a temperature span higher than the single material $\mathrm{La}(\mathrm{Fe}, \mathrm{Co}, \mathrm{Si})_{13}$ regenerator, suggesting that the two materials are not a good combination for this device and regenerator geometry. A second layered $\mathrm{La}(\mathrm{Fe}, \mathrm{Co}, \mathrm{Si})_{13}$ regenerator with transition temperatures of $13{ }^{\circ} \mathrm{C}$ and $16{ }^{\circ} \mathrm{C}$ was constructed and tested. The temperature 
span achieved by the device as a function of ambient temperature is shown in Fig. 5. In order to compare the measured performance of all $\mathrm{La}(\mathrm{Fe}, \mathrm{Co}, \mathrm{Si})_{13}$, results for the $3{ }^{\circ} \mathrm{C}$ and $16{ }^{\circ} \mathrm{C}$ layered bed and single-material regenerators of 13 and $16{ }^{\circ} \mathrm{C} \mathrm{La}(\mathrm{Fe}, \mathrm{Co}, \mathrm{Si})_{13}$ are also shown.

The data for the layered bed of 3 and $16{ }^{\circ} \mathrm{C}$ shown in Fig. 5 were taken for a higher fluid velocity than for the layered by of $13{ }^{\circ} \mathrm{C}$ and $16{ }^{\circ} \mathrm{C}$. The 3 and $16{ }^{\circ} \mathrm{C}$ regenerator was damaged and results could not be obtained for teh lower flow rates presented for the 13 and $16{ }^{\circ} \mathrm{C}$ regenerator. However, the 13 and $16{ }^{\circ} \mathrm{C}$ regenerator was run at the higher flow rates shown for the 3 and $16{ }^{\circ} \mathrm{C}$ regenerator and the measured no-load temperature span was approximately $0.5{ }^{\circ} \mathrm{C}$ lower than the results shown in Fig. 5. Therefore, it is most likely that the performance of the layered $3{ }^{\circ} \mathrm{C}$ and $16{ }^{\circ} \mathrm{C}$ regenerator is still significantly below that of the $13{ }^{\circ} \mathrm{C}$ and $16{ }^{\circ} \mathrm{C}$ regenerator, even though the performance of the former would likely improve if the experiments were performed with a lower fluid velocity. The $13{ }^{\circ} \mathrm{C}$ and $16{ }^{\circ} \mathrm{C}$ layered regenerator also outperforms the single material $\mathrm{La}(\mathrm{Fe}, \mathrm{Co}, \mathrm{Si})_{13}$ operating at its optimal conditions by a small margin; however, the Gd regenerator is still able to produce a higher no-load temperature span. As was observed with Gd, the regenerator performs best when the transition temperature of the regenerator is between the hot and cold reservoir temperatures. This experiment shows that it is possible to improve AMR performance by using a layered regenerator of $\mathrm{La}(\mathrm{Fe}, \mathrm{Co}, \mathrm{Si})_{13}$ plates when the transition temperatures of the layers are chosen correctly. Examination of Fig. 2 shows that there is a relatively large temperature region between the $3^{\circ} \mathrm{C} \mathrm{La}(\mathrm{Fe}, \mathrm{Co}, \mathrm{Si})_{13}$ material and the $16{ }^{\circ} \mathrm{C}$ material where the magnetocaloric effect is relatively small. 
On the other hand, the $13{ }^{\circ} \mathrm{C}$ and $16{ }^{\circ} \mathrm{C} \mathrm{La}(\mathrm{Fe}, \mathrm{Co}, \mathrm{Si})_{13}$ materials have magnetocaloric properties that are so similar, that the magnetocaloric effect in the lower temperature region of the regenerator is only enhanced by a small amount. For example, a regenerator made of 10 and $16{ }^{\circ} \mathrm{C} \mathrm{La}(\mathrm{Fe}, \mathrm{Co}, \mathrm{Si})_{13}$ would likely perform better than the $\mathrm{La}(\mathrm{Fe}, \mathrm{Co}, \mathrm{Si})_{13}$ regenerators presented here.

\subsubsection{Reducing oxidation of $(\mathrm{Fe}, \mathrm{Co}, \mathrm{Si})_{13}$ plates}

It was observed that the $(\mathrm{Fe}, \mathrm{Co}, \mathrm{Si})_{13}$ plates used in experiments presented here were very susceptible to corrosion in water. Although additives to the heat transfer fluid have been shown to greatly reduce corrosion, it has not been proven effective over a long period or for extended use. An alternative method of corrosion protection is to coat the plates with a thin polymer layer. Plates of $13{ }^{\circ} \mathrm{C} \mathrm{La}(\mathrm{Fe}, \mathrm{Co}, \mathrm{Si})_{13}$ that were coated with a thin layer of polymer were provided by Vacuumschmeltze GmbH. The coating is thin enough that its thermal resistance due to conduction is significantly less than the thermal resistance due to convection at the plate surface, which indicates that the coating should have a minimal impact on heat transfer in the regenerator. The impact of using the coated plates was tested by comparing the performance of the AMR using the coated plates to the uncoated plates. The device was run at a single ambient temperature and utilization for a range of cooling powers, and the results are shown in Fig. 6. The ambient temperature for the experiments presented in Fig. 6 is approximately $12{ }^{\circ} \mathrm{C}$ and the utilization is 0.76 .

The results in Fig. 6 show that the coating does not significantly affect the performance, which means that thermal resistance of the coating is negligible 
for the operating conditions considered here and the convection heat transfer rate at the plate surface is approximately equal. However, the coating was found to be easily scratched off, reducing the corrosion resistance. It was important to handle each plate carefully during assembly to ensure that the coating was not damaged.

\subsection{Results for an LCSM regenerator}

The final magnetocaloric material tested in this device is LCSM. This material has a lower adiabatic temperature change than $\mathrm{Gd}$, is corrosion resistant and can be made at a lower cost. The ceramic powder was suspended in a slurry and tape casted into sheets that were then sintered. The final thickness of the plates is approximately $0.3 \mathrm{~mm}$. Because the regenerator housings described in previous sections can be manufactured with a minimum $0.5 \mathrm{~mm}$ plate spacers, the lowest possible porosity for the LCSM regenerator would be approximately 0.6 , which is significantly higher than the regenerators with $0.9 \mathrm{~mm}$ plates. Therefore, a different method was used to construct the LCSM regenerator.

The LCSM regenerator blocks were fabricated using thin wire spacers to regulate the plate spacing. Sections of wire with a diameter of $0.2 \mathrm{~mm}$ were stretched slightly to produce a straight wire with no sharp bends. The regenerator was stacked with wires between each plate and a total of 20 plates were used. After all the plates were stacked, the stack was compressed slightly to reduce the effects of slight bending of the wires and the plates were bonded with epoxy on both sides along the entire length of the plates in the flow direction. The resulting regenerator stack height was measured, and the effective plate spacing was approximately $0.23 \mathrm{~mm}$. The discrepancy 
between the wire diameter and the effective plate spacing is most likely do to non-uniform flatness and thickness of the plates, slight bending in the wire spacers, or possibly from variations introduced when the epoxy was applied. The volume of magnetocaloric material in the LCSM regenerator block is approximately $50 \%$ of the other regenerators discussed, so the fluid flow was adjusted to yield approximately the same utilizations. However, it should be noted that the LCSM regenerator is a smaller regenerator but has the same system losses experienced by the other regenerators. Therefore, losses to the ambient have a larger impact on the LCSM regenerator than the other regenerators presented here. With a transition temperature of approximately $23{ }^{\circ} \mathrm{C}$, the ambient temperature for testing was set to $25^{\circ} \mathrm{C}$ to ensure the regenerator operated near its optimal temperature. The regenerator was operated over a range of cycle times and utilizations. The no-load temperature spans were not highly dependent on cycle time, which is controlled by fluid velocity for a given utilization, but there was a dependence on the optimal cycle time and utilization. As the utilization increases, the optimum cycle time increases, and the optimum fluid velocity decreases, but the optimum cycle time is near $10 \mathrm{~s}$ for each utilization. The no-load temperature span for the optimal cycle time is shown as a function of utilization in Fig. 7.

The temperature span achieved by the LCSM regenerator with a utilization of approximately 0.5 at two different cycle times and cooling powers is given in Fig. 8.

Figure 8 shows that a regenerator made of LCSM produces a maximum no-load temperature span of $5.1^{\circ} \mathrm{C}$, which is lower than regenerators made of Gd or $\mathrm{La}(\mathrm{Fe}, \mathrm{Co}, \mathrm{Si})_{13}$ compounds, despite having smaller plate spacing and 
therefore higher theoretical heat transfer in the regenerator. However, the regeneration ratio for the LCSM regenerator is approximately 5.1, and the effect of fluid velocity is greatly decreased due to the smaller channel spacing. The LCSM regenerator exhibited the highest $\zeta$ of the regenerators presented in this paper, most likely due to the smaller plate spacing and relatively high specific heat of LCSM. In Fig. 8, the no-load temperature span only decreases a small amount when the fluid velocity is increased dramatically. For the 4 s cycle time, the fluid velocity is more than 5 times that for the $10 \mathrm{~s}$, but the no-load temperature span is only slightly reduced. When a heating load is applied to the cold reservoir, the temperature span achieved by the $4 \mathrm{~s}$ cycle is significantly higher because the magnetocaloric material is magnetized and demagnetized more often, allowing the material to transfer more energy.

Although the LCSM regenerator did not perform as well as the other regenerators presented here, the material family still represents a possibly attractive magnetocaloric material for AMR applications because The transition temperature of LCSM compounds can be adjusted over a large temperature range by the material composition. A single plate consisting of multiple transition temperatures can be tape casted. This method can be used to improve LCSM regenerator performance without increasing the complexity of assembly. It is also corrosion resistance and has a relatively low cost.

\subsubsection{Combined Magnetization and Flow Periods for the LCSM Regenerator}

Because the fluid flow period and magnetization periods can be controlled independently of each other, the effect of the relative timing of the two pro- 
cesses can be studied. The control software of the test machine was modified so that the beginning of the magnetization or demagnetization process was also the beginning of the fluid flow process. The main changes to the cycle that occur from combining the magnetization and fluid flow are that heat transfer occurs as the temperature of the magnetocaloric material is changing due to the change in magnetic field, and the cycle time is also reduced. The combined cycle consists of a simultaneous magnetization and cold-to-hot blow of approximately $2 \mathrm{~s}$ and a simultaneous demagnetization and hot-tocold blow that lasts approximately $2 \mathrm{~s}$. In each combined process, the fluid displacer starts moving at the same time the the regenerator begins to move, and the blow period ends after the displacer has come to rest. The fast cycle results are also plotted with the standard cycle in Fig. 8. For every test case, the fast cycle produced a higher temperature span for the same cooling load. For the case of a utilization of 0.54 , the faster cycle increases the no-load temperature span from 5.1 to $5.8^{\circ} \mathrm{C}$. Although a $0.7^{\circ} \mathrm{C}$ increase in temperature span is small, it represents an improvement from a $\zeta$ of 5.1 to 5.8 and is a significant increase for the LCSM regenerator in the AMR presented here.

\section{Conclusions}

This paper presented experimental results for a simple flat plate AMR composed of $\mathrm{Gd}, \mathrm{La}(\mathrm{Fe}, \mathrm{Co}, \mathrm{Si})_{13}$ compounds, and an LCSM compound. The best performance was achieved for a single-material Gd regenerator. The maximum no-load temperature span produced by the Gd AMR was 10.2 ${ }^{\circ} \mathrm{C}$. The device was also tested with single material $\mathrm{La}(\mathrm{Fe}, \mathrm{Co}, \mathrm{Si})_{13}$ regenerators and two different two-material $\mathrm{La}(\mathrm{Fe}, \mathrm{Co}, \mathrm{Si})_{13}$ regenerators. One of 
the two-material $\mathrm{La}(\mathrm{Fe}, \mathrm{Co}, \mathrm{Si})_{13}$ regenerators demonstrated improved AMR performance over a single-material AMR when the transition temperatures of the materials were $13{ }^{\circ} \mathrm{C}$ and $16{ }^{\circ} \mathrm{C}$. The two-material experiments show that it is important to select the correct transition temperatures of each material based on the heat transfer characteristics and cycle parameters of the AMR where the material will be used. Using a thin polymer coating of the $\mathrm{La}(\mathrm{Fe}, \mathrm{Co}, \mathrm{Si})_{13}$ plates was shown to have a minor impact on AMR performance and could be viable method to reduce corrosion in the AMR.

An LCSM regenerator was also tested but did not perform as well as the other materials tested in the this paper. However, the LCSM regenerator demonstrated that a flat plate regenerator with thinner plates and smaller plate spacing can operate at higher cycle frequencies and produces higher regeneration ratios. It was found that higher performance can be achieved by combining the magnetization/demagnetization processes with the fluid flow processes, thus lowering the cycle time.

\section{Acknowledgements}

The authors would like to acknowledge the support of the Programme Commission on Energy and Environment (EnMi) (Contract No. 2104-060032) which is part of the Danish Council for Strategic Research. Also, we thank Dr. Matthias Katter of Vacuumschmelze GmbH \& Co. KG, Hanau, Germany for supplying the plates of $\mathrm{La}(\mathrm{Fe}, \mathrm{Co}, \mathrm{Si})_{13}$. The technical support of Jørgen Geyti and assistance from Sedi Byskov are greatly appreciated. 
Bahl, C. R. H., Petersen, T., Pryds, N., Smith, A., Petersen, T., 2008. A versatile magnetic refrigeration test device. Review of Scientific Instruments 79 (9), 093906.

Barclay, J. A., Sarangi, S., 1984. Selection of regenerator geometry for magnetic refrigerator applications. In: ASME winter annual meeting.

Bjørk, R., Bahl, C. R. H., Katter, M., 2010. Magnetocaloric properties of $\mathrm{LaFe}_{13-x-y} \mathrm{Co}_{x} \mathrm{Si}_{y}$ and commercial grade Gd. Journal of Manetism and Magnetic Materials 322, 3882-3888.

Bjørk, R., Bahl, C. R. H., Smith, A., Pryds, N., 2010. Review and comparison of magnet designs for magnetic refrigeration. International Journal of Refrigeration 33, 437-448.

Dan'kov, S., Tishin, A., Pecharsky, V., Gschneidner, K.A., J., 1998. Magnetic phase transitions and the magnetothermal properties of gadolinium. Physical Review B (Condensed Matter) 57 (6), 3478-3490.

Dinesen, A. R., 2004. Magnetocaloric and magnetoresistive properties of $\mathrm{la}_{0.67} \mathrm{Ca}_{0.33-x} \mathrm{Sr}_{x} \mathrm{mno}_{3}$. Ph.D. thesis, Ris $\varnothing$ National Laboratory, Denmark.

Dragutinovic, G. D., Baclic, B. S., 1998. Operation of Counterflow Regenerators. Computational Mechanics Inc., Billerica, MA.

Engelbrecht, K., Jensen, J. B., Bahl, C. R. H., Pryds, N., 2009. Experiments on a modular magnetic refrigeration device. Proceedings of the $3^{\text {rd }}$ International Conference on Magnetic Refrigeration at Room Temperature, Des Moines, Iowa, USA, 431-436. 
Engelbrecht, K. L., Nellis, G. F., Klein, S. A., 2006. Predicting the performance of an active magnetic regenerator refrigerator used for space cooling and refrigeration. HVAC and R Research 12 (4), 1077-1095.

Gschneidner, K.A., J., Pecharsky, V., 2008. Thirty years of near room temperature magnetic cooling: Where we are today and future prospects. International Journal of Refrigeration 31 (6), 945-961.

Gschneidner Jr, K. A., Pecharsky, V. K., Tsokol, A. O., 2005. Recent developments in magnetocaloric materials. Rep. Prog. Phys 68, 1479-1539.

Lu, D. W., Xu, X. N., Wu, H. B., Jin, X., 2005. A permanent magnet magneto-refrigerator study on using gd/gd-si-ge/ gd-si-ge-ga alloys. Proceedings of the $1^{\text {st }}$ International Conference on Magnetic Refrigeration at Room Temperature, Montreux, Switzerland, 1-6.

Nakamura, K., Ikegawa, M., Kawanami, T., Hirano, S., Fumoto, K., 2008. Improvement of room temperature magnetic refrigerator using air as heat transfer fluid. In: $2^{\text {nd }}$ International Conference on Thermal Issues in Emerging Technologies.

Rowe, A., Tura, A., 2006. Experimental investigation of a three-material layered active magnetic regenerator. International Journal of Refrigeration 29(8), 1286-1293.

Sarlah, A., 2008. Thermo-hydraulic properties of heat regenerators in magnetic refrigerator. Ph.D. thesis, University of Ljubljana, Slovenia.

Tura, A., Rowe, A., 2009. Progress in the characterization and optimization 
of a permanent magnet magnetic refrigerator. Proceedings of the $3^{\text {rd }}$ International Conference on Magnetic Refrigeration at Room Temperature, Des Moines, Iowa, USA, 387-392.

Yu, B., Gao, Q., Zhang, B., Meng, X., Chen, Z., 2003. Review on research of room temperature magnetic refrigeration. International Journal of Refrigeration 26 (6), 622-636.

Zimm, C., Boeder, A., Chell, J., Sternberg, A., Fujita, A., Fujieda, S., Fukamichi, K., 2006. Design and performance of a permanent-magnet rotary refrigerator. International Journal of Refrigeration 29 (8), 1302-1306. 


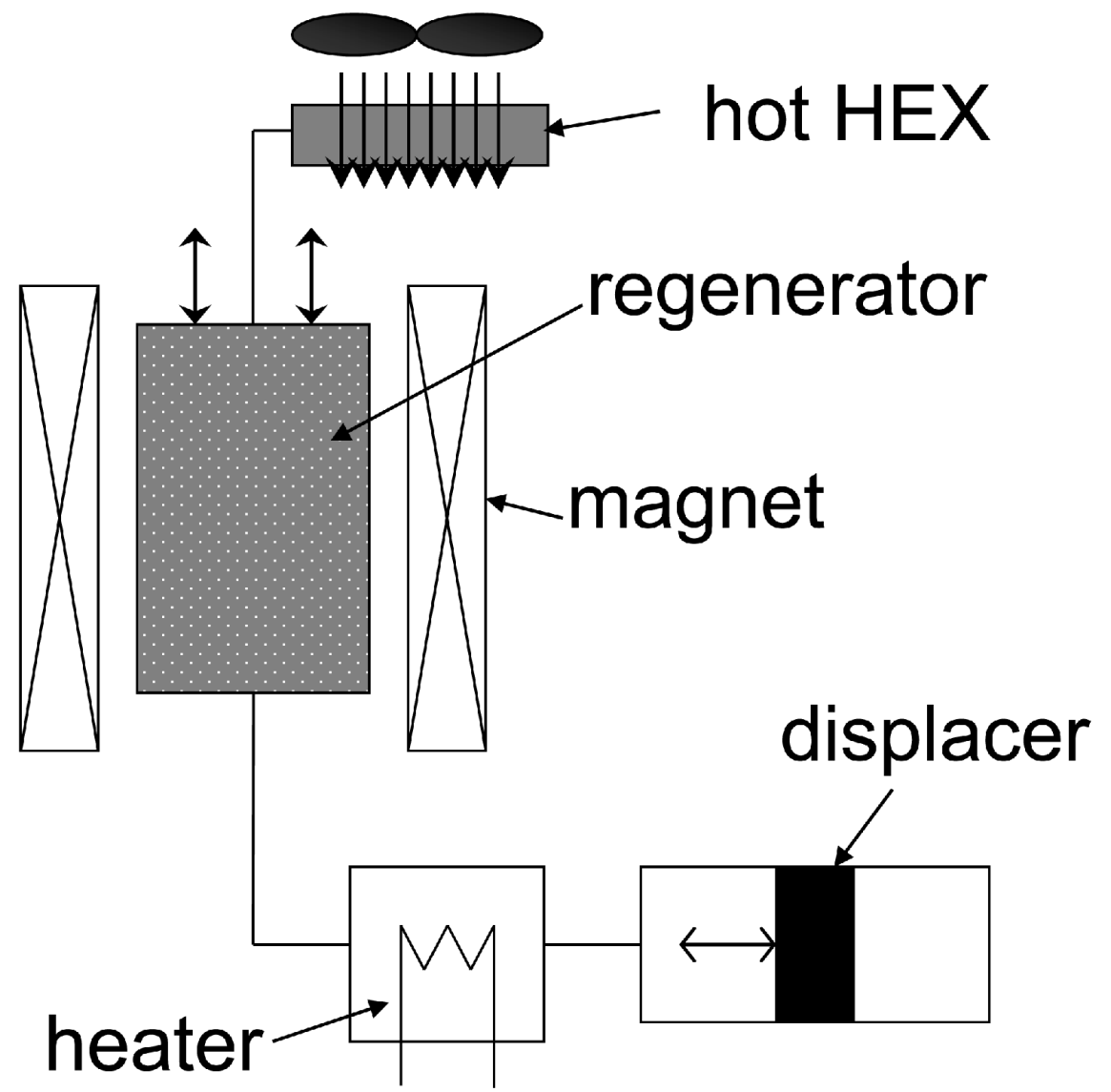

Figure 1 


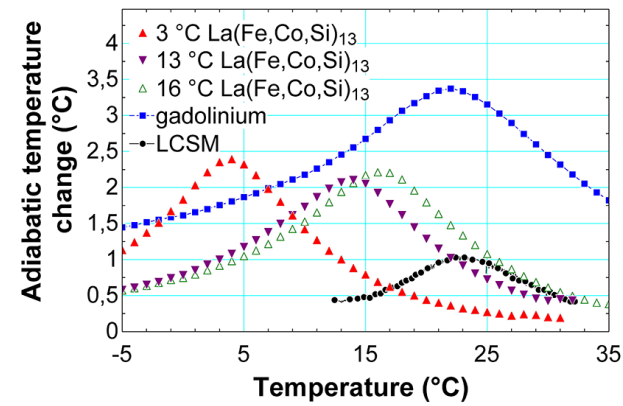

(a)

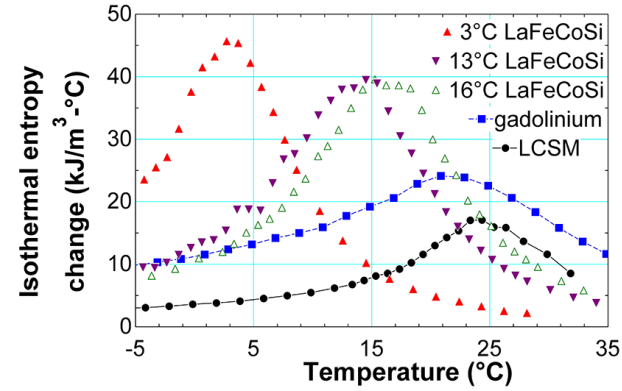

(b)

Figure 2 


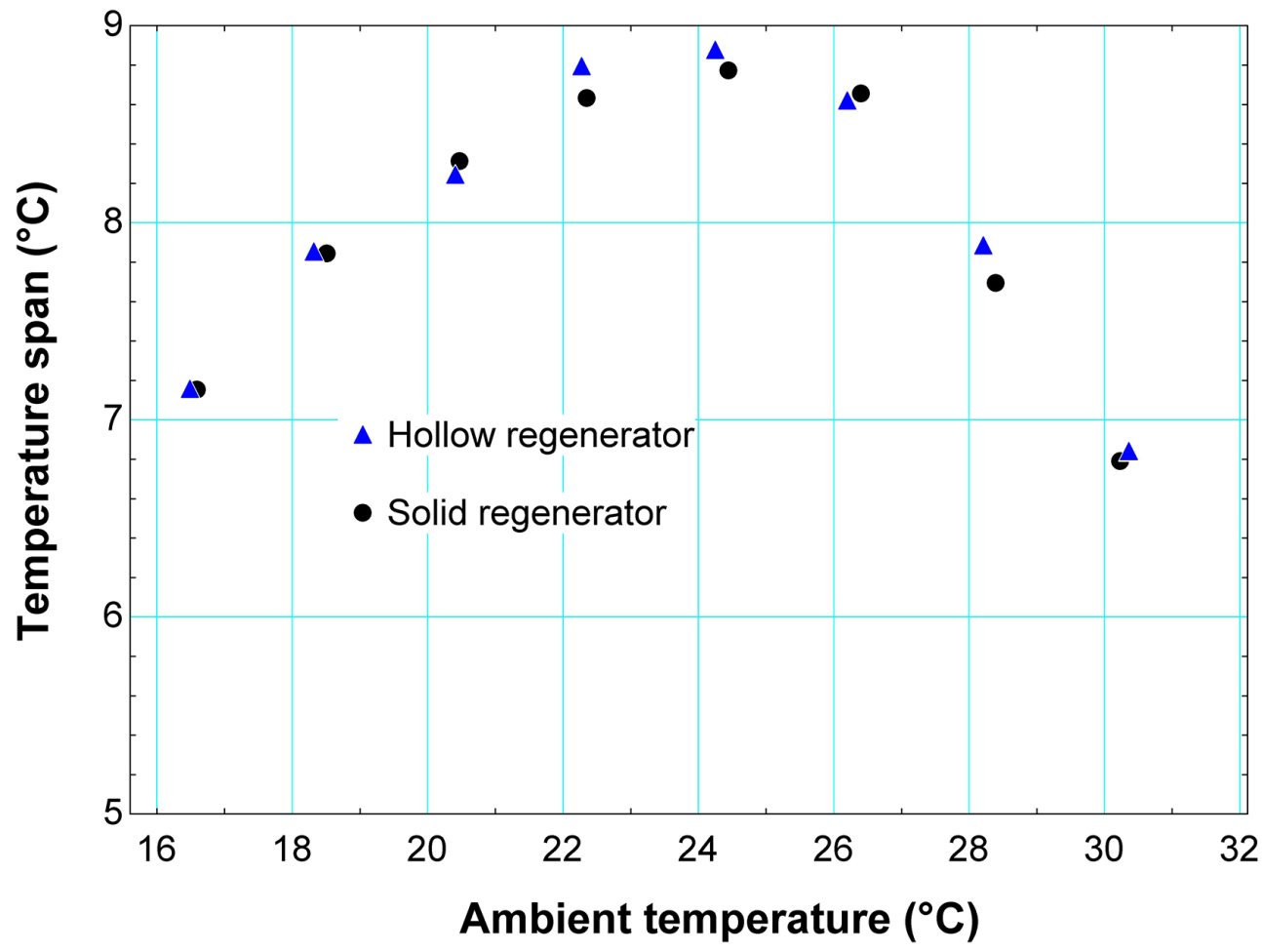

Figure 3 


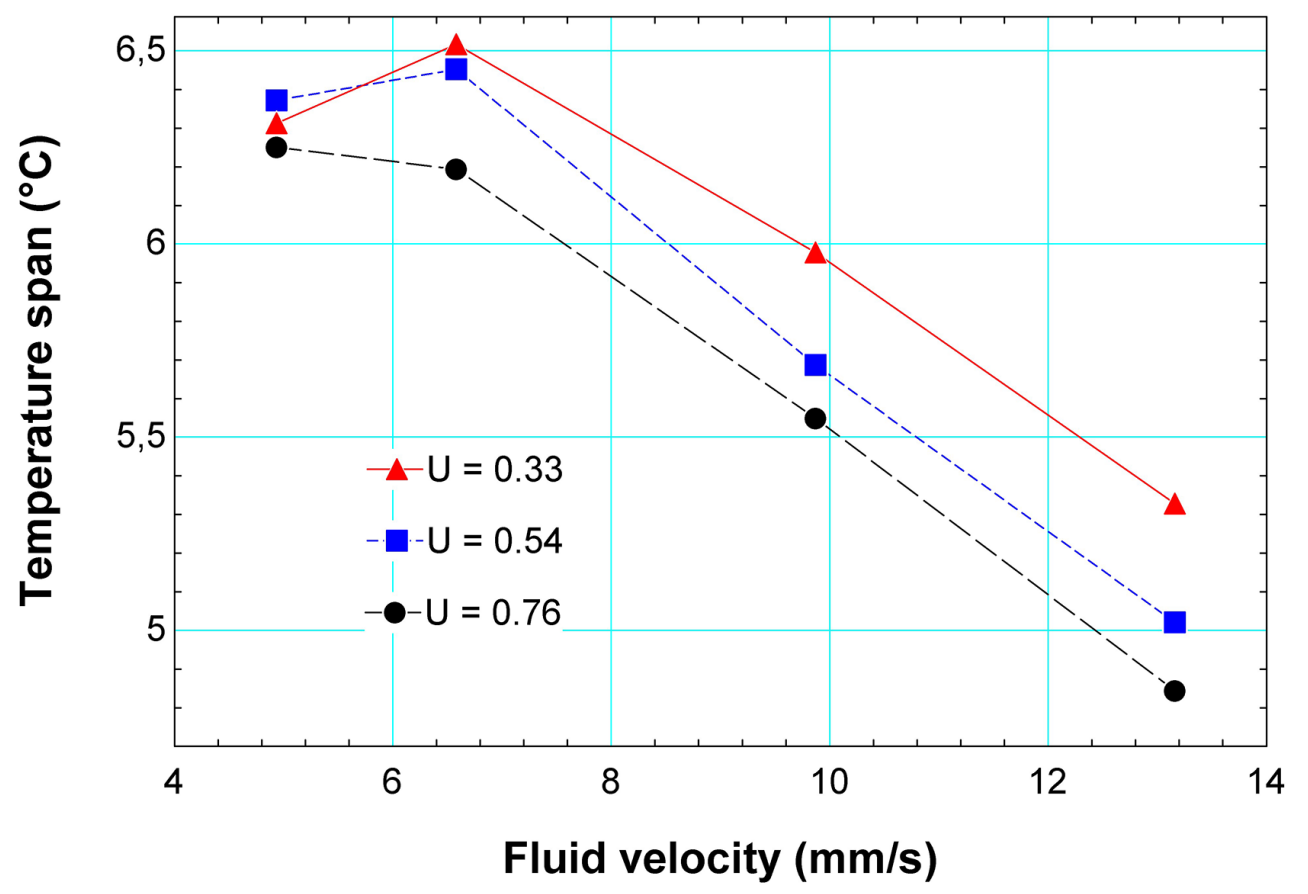

Figure 4 


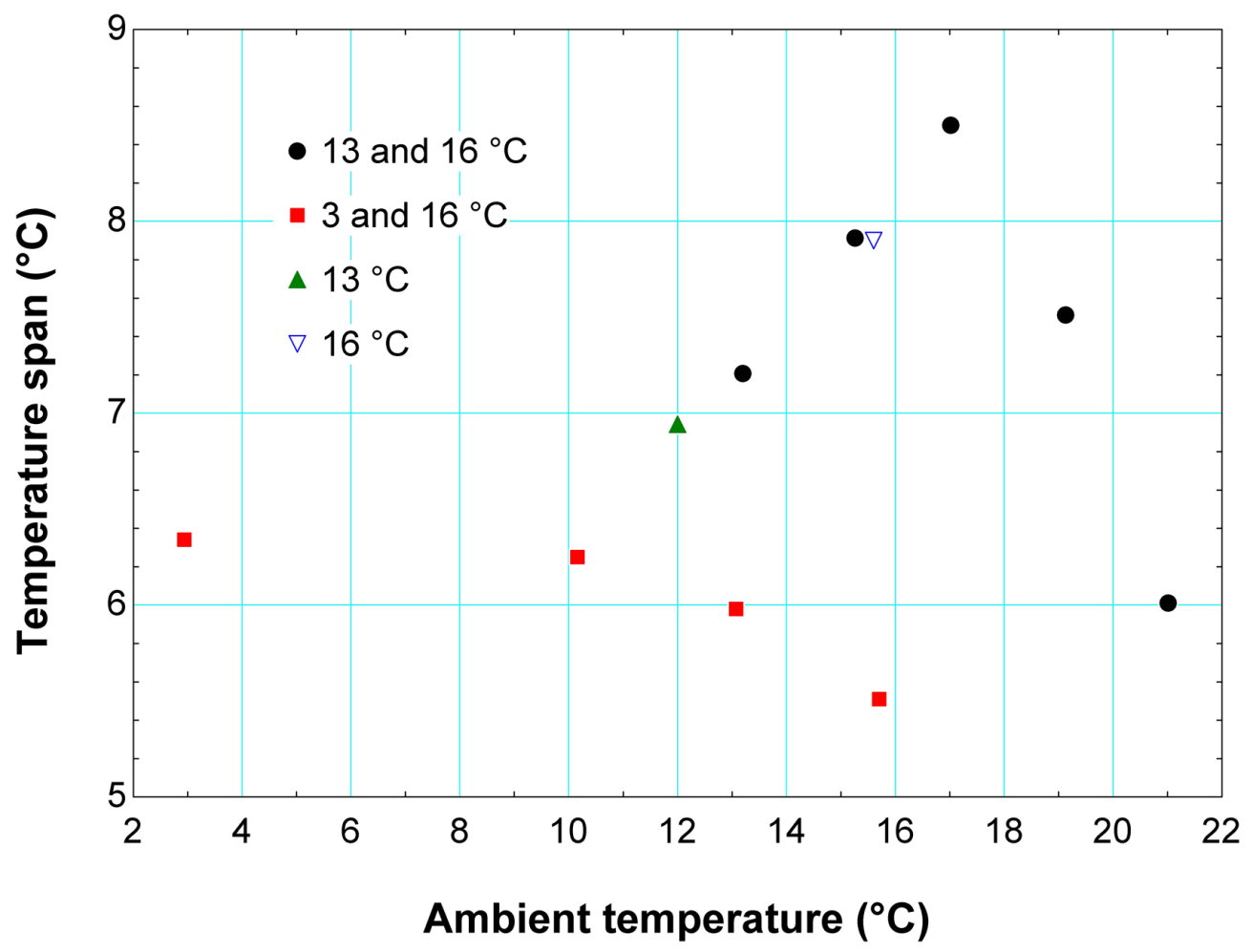

Figure 5 


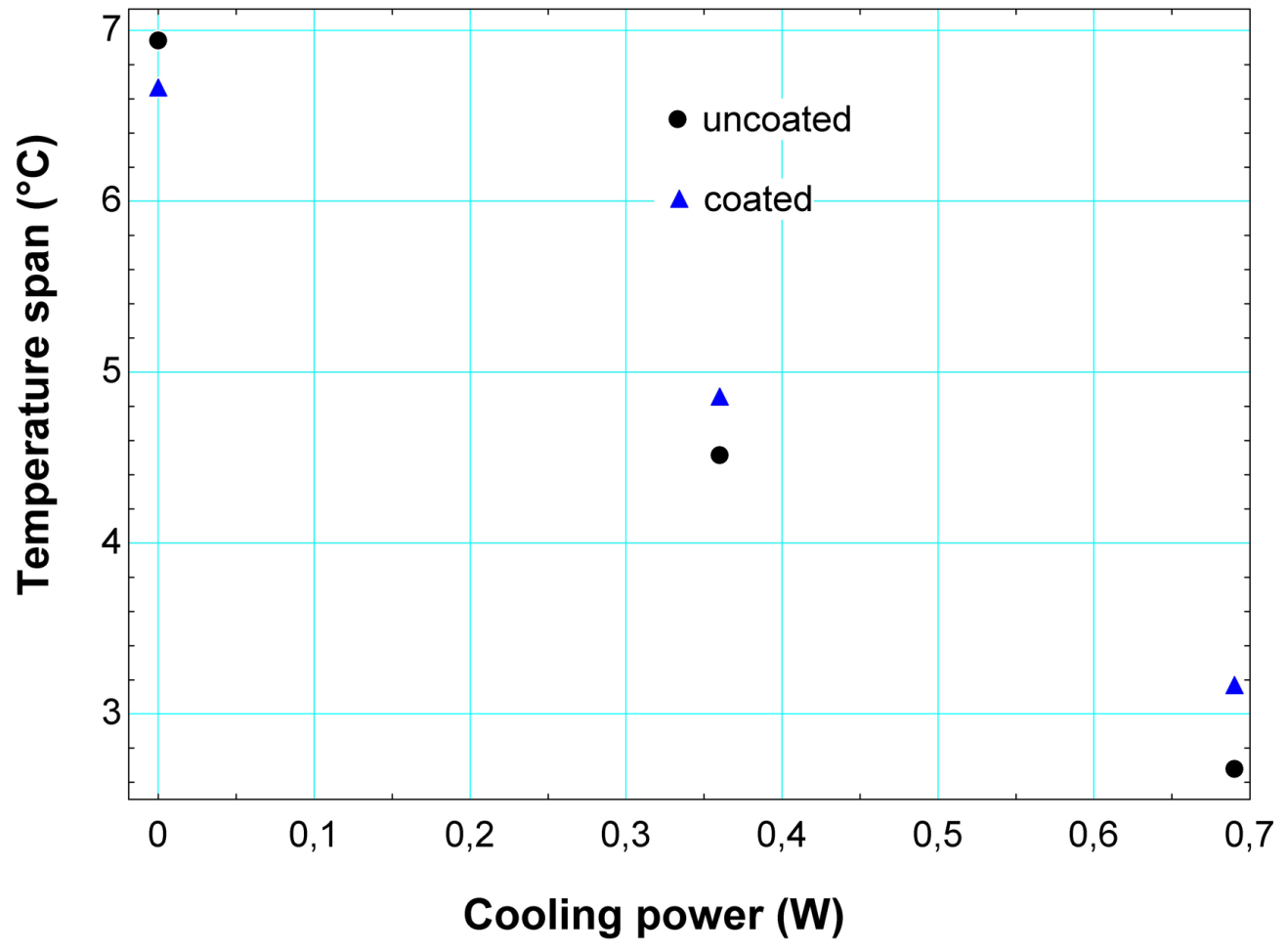

Figure 6 


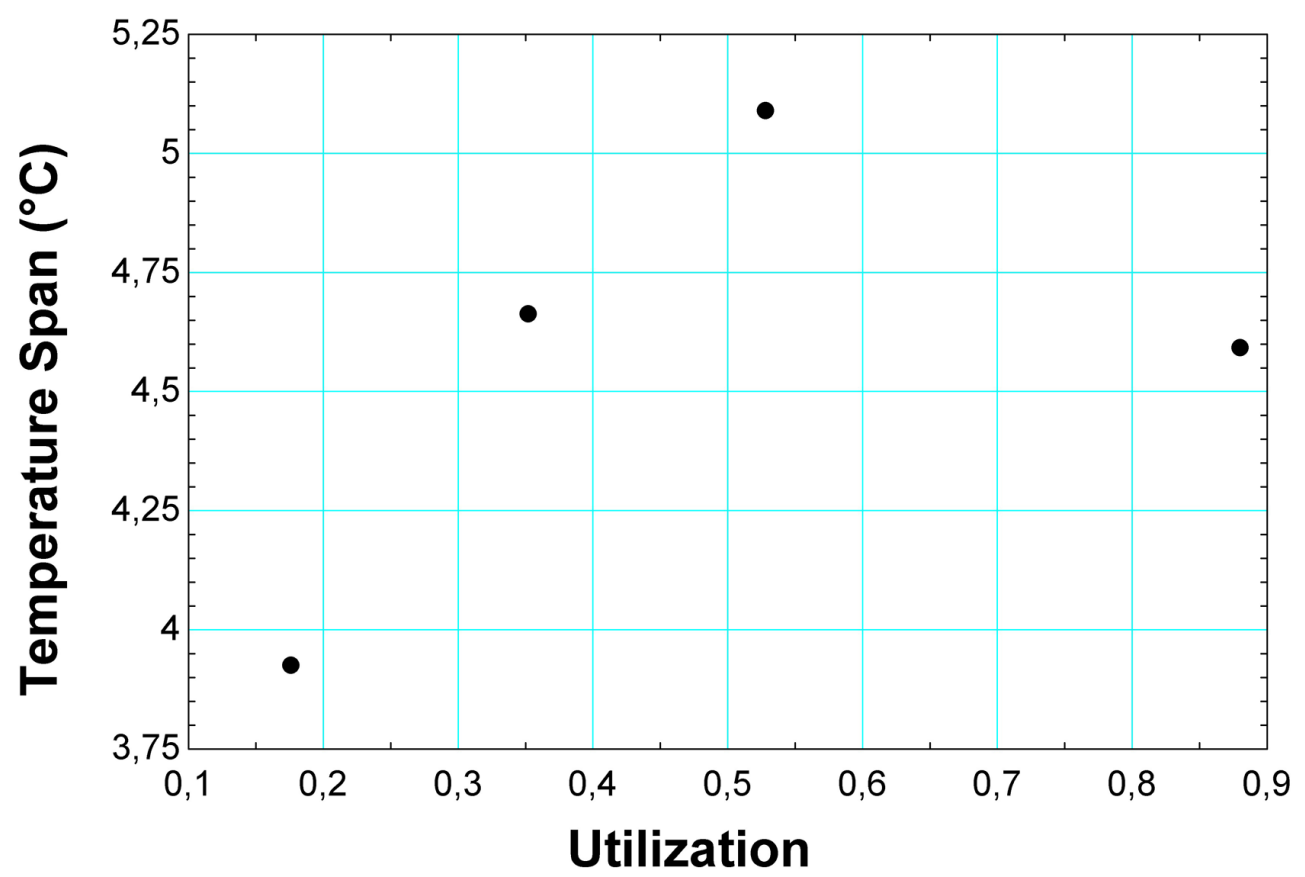

Figure 7 


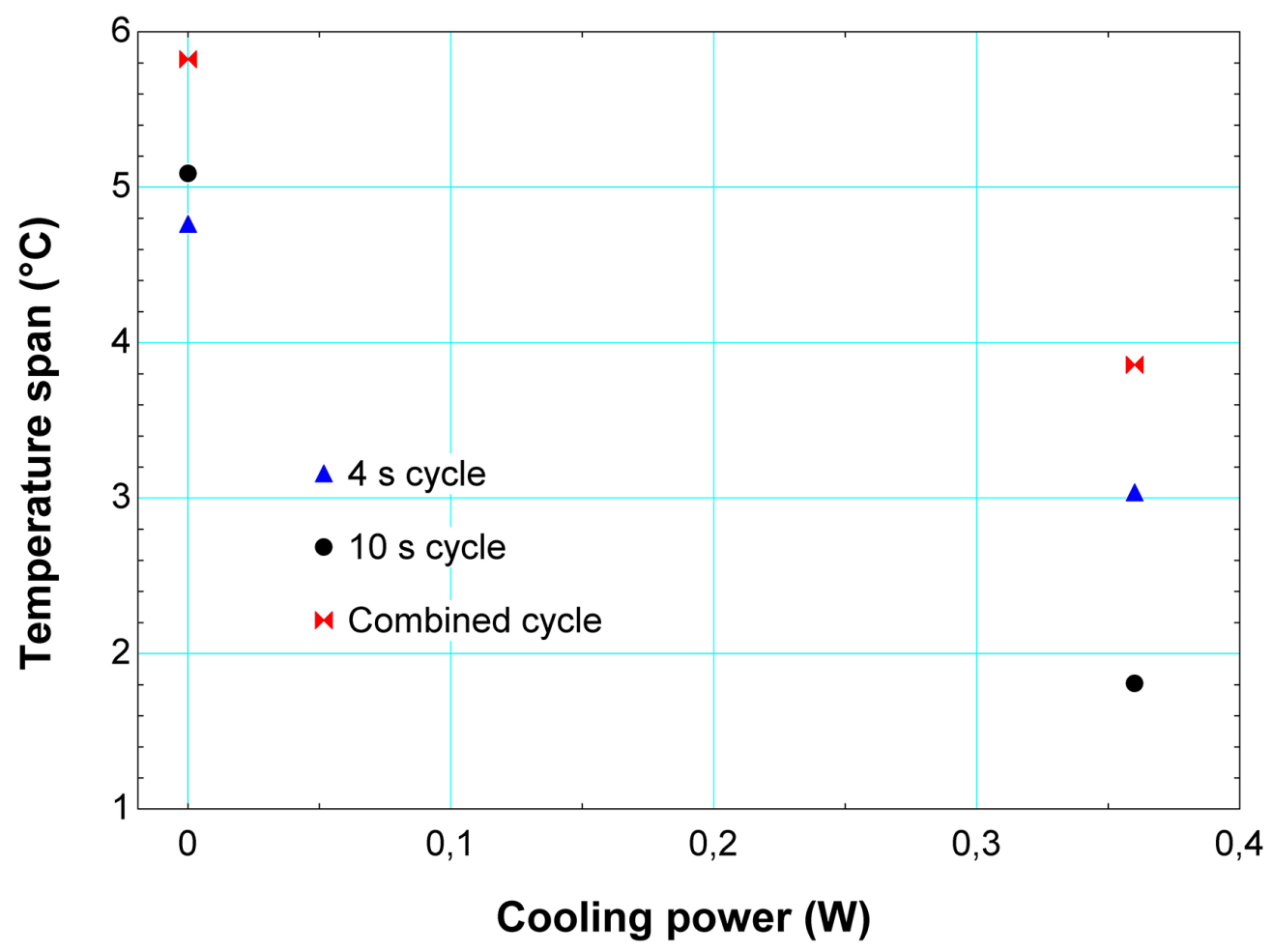

Figure 8 
Fig. 1: Schematic of the single-bed test machine.

Fig. 2: The adiabatic temperature change (a) and volumetric isothermal entropy change (b) when magnetized from 0 to 1 Tesla as a function of temperature.

Fig. 3: No load temperature span as a function of ambient temperature for the operating conditions shown in Table III for Gd for the standard regenerator housing and the housing with hollow walls.

Fig. 4: No load temperature span as a function of fluid velocity for a two-material $\mathrm{La}(\mathrm{Fe}, \mathrm{Co}, \mathrm{Si})_{13}$ regenerator with transition temperatures of 3 and $16{ }^{\circ} \mathrm{C}$ operating in an ambient temperature of $13^{\circ} \mathrm{C}$.

Fig. 5: No-load temperature span as a function of ambient temperature for a two-material $\mathrm{La}(\mathrm{Fe}, \mathrm{Co}, \mathrm{Si})_{13}$ regenerator with transitions temperatures of $13{ }^{\circ} \mathrm{C}$ and $16{ }^{\circ} \mathrm{C}$ as well as a layered bed of $3{ }^{\circ} \mathrm{C}$ and $16{ }^{\circ} \mathrm{C}$ and single-material beds of $13{ }^{\circ} \mathrm{C}$ and $16{ }^{\circ} \mathrm{C}$.

Fig. 6: No-load temperature span as a function of cooling power for plates coated with a thin polymer layer and uncoated $\mathrm{La}(\mathrm{Fe}, \mathrm{Co}, \mathrm{Si})_{13}$ plates with a Curie temperatures of 13 ${ }^{\circ} \mathrm{C}$

Fig. 7: Temperature span as a function of utilization for a single material LCSM regenerator. Each temperature span is reported at the cycle time that yielded the highest value. 
Fig. 8: Temperature span as a function of cooling power for a single material LCSM regenerator for two different cycle times.

Table I: Approximate mass of a regenerator comprised of different magnetocaloric materials.

\begin{tabular}{cc}
\hline Material & Mass of solid material \\
\hline gadolinium & $78.2 \mathrm{~g}$ \\
\hline $\mathrm{La}(\mathrm{Fe}, \mathrm{Co}, \mathrm{Si})_{13}$ & $71.3 \mathrm{~g}$ \\
\hline $\mathrm{LCSM}$ & $34.1 \mathrm{~g}$ \\
\hline
\end{tabular}

Table II: Property values used to calculate operating parameters.

\begin{tabular}{cc}
\hline Parameter & Value \\
\hline specific heat Gd & $260 \mathrm{Jkg}^{-1} \mathrm{~K}^{-1}$ \\
\hline specific heat La $(\mathrm{Fe}, \mathrm{Co}, \mathrm{Si})_{13}$ & $450 \mathrm{Jkg}^{-1} \mathrm{~K}^{-1}$ \\
\hline specific heat LCSM & $600 \mathrm{Jkg}^{-1} \mathrm{~K}^{-1}$ \\
\hline density Gd & $7900 \mathrm{kgm}^{-3}$ \\
\hline specific heat La $(\mathrm{Fe}, \mathrm{Co}, \mathrm{Si})_{13}$ & $7200 \mathrm{kgm}^{-3}$ \\
\hline specific heat LCSM & $5500 \mathrm{kgm}^{-3}$ \\
\hline fluid specific heat & $3852 \mathrm{Jkg}^{-1} \mathrm{~K}^{-1}$ \\
\hline$\Delta T_{a d} \mathrm{Gd}$ & $3.2{ }^{\circ} \mathrm{C}$ \\
\hline$\Delta T_{a d} \mathrm{La}(\mathrm{Fe}, \mathrm{Co}, \mathrm{Si})_{13}$ & $1.8{ }^{\circ} \mathrm{C}$ \\
\hline$\Delta T_{a d} \mathrm{LCSM}$ & $1.0{ }^{\circ} \mathrm{C}$ \\
\hline
\end{tabular}


Table III: Operating conditions that result in the highest no-load temperature span for the Gd regenerator.

\begin{tabular}{cc}
\hline Parameter & Value Unit \\
\hline Cycle period $(\tau)$ & $8 \mathrm{~s}$ \\
\hline Utilization & 0.55 \\
\hline Fluid velocity & $8.2 \mathrm{~mm} \mathrm{~s}^{-1}$ \\
\hline
\end{tabular}

